شبيه سازى آب زيرزمينى حوزه آبخيز قائمشهر جويبار در شرايط اجراى

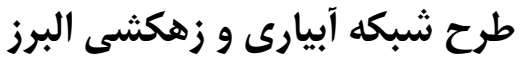

\author{
زهرا قربانى سرهنكَى '، على شاهنظرى '، محمدعلى غلامى سفيدكوهى 'و سميه جنت رستمىع

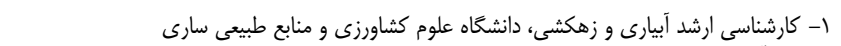

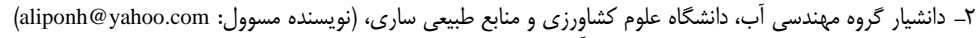

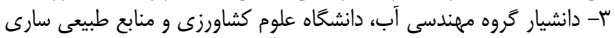

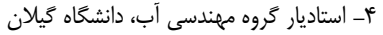

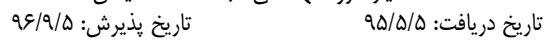

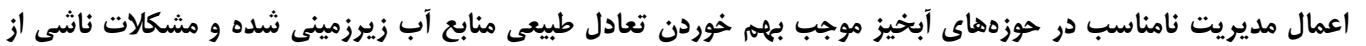

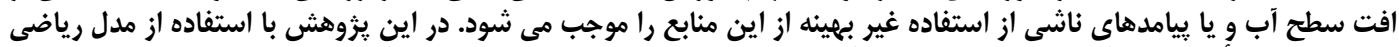
MODFLOW

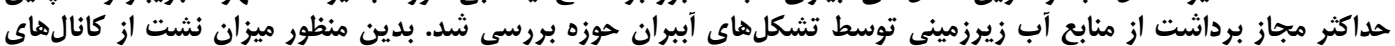

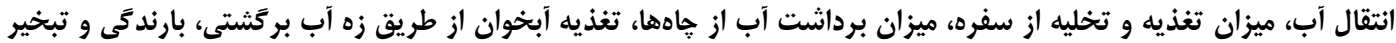

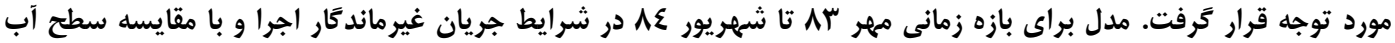

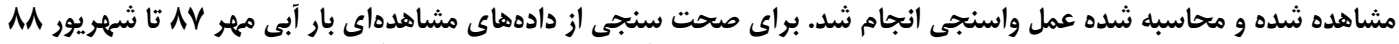

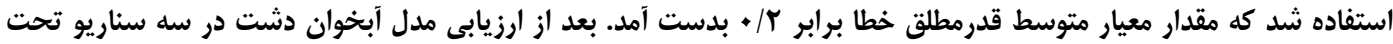

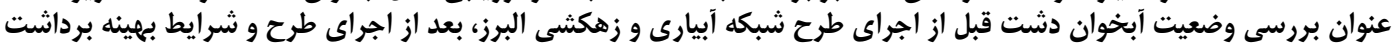

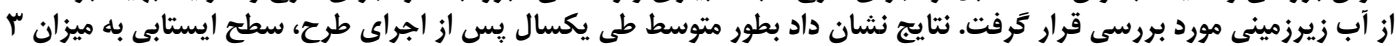

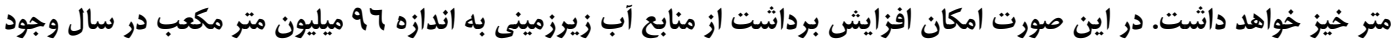

وازمهاى كليدى: تشكل آب بران، حداكثر مجاز برداشت، سطح ايستابى، مديريت آبخوان، مدل MODFLOW

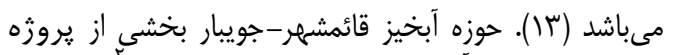

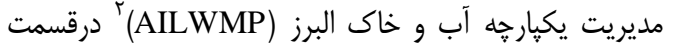

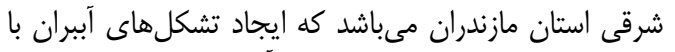

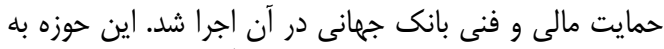

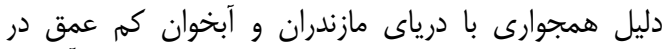

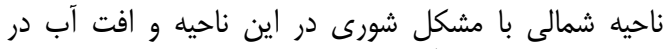

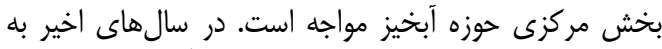

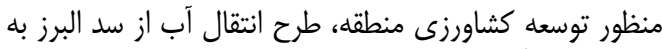

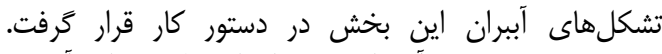

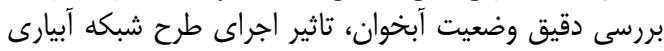

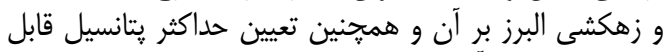

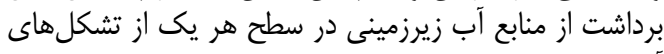

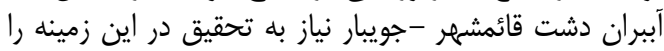
به وجود آورده است.

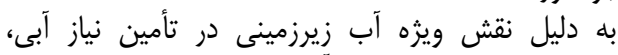

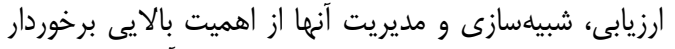

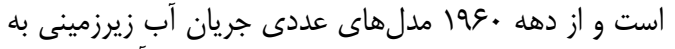

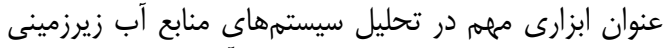

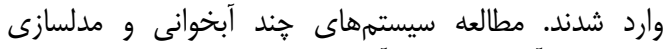

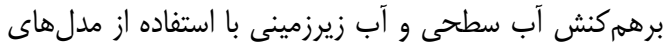

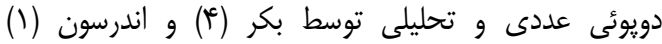

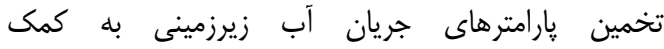

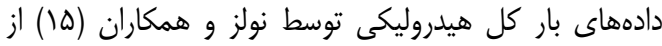

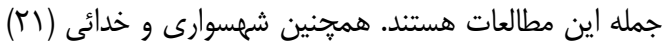

آب نياز اوليه و اساسى براى حفظ بقاء، توسعه صنايع و ورتو

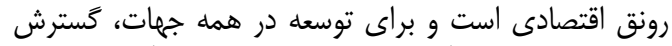

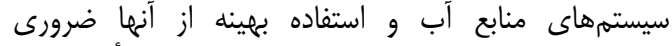

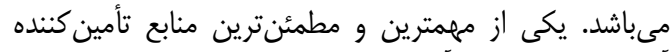

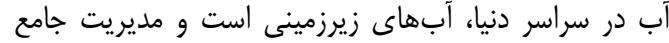

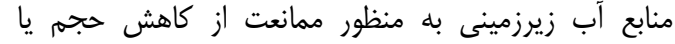

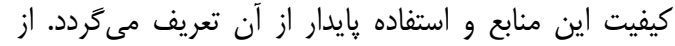

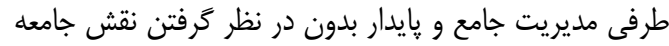

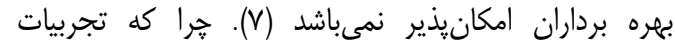

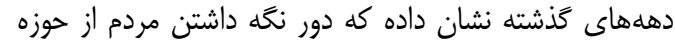

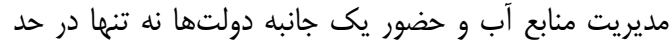

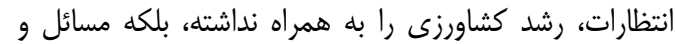

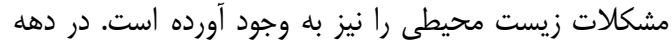

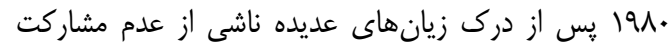

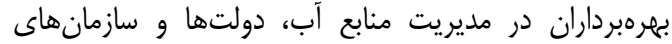

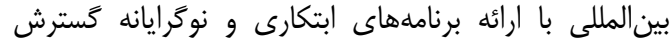

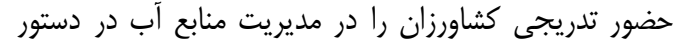

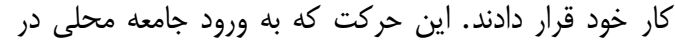

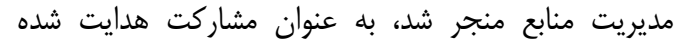

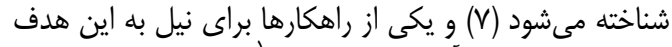

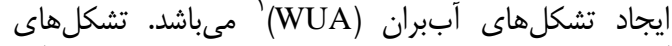

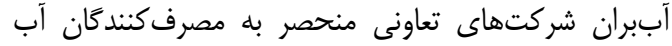
است كه هدفشان بهرهبردارى بهيينه از سيستمهاى منابع آب آب 
آب سطحى و زيرزمينى خواهد بود. كريمى يور و همكاران

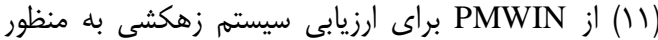

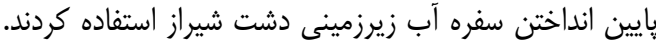

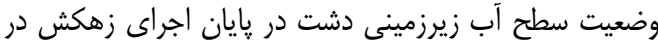

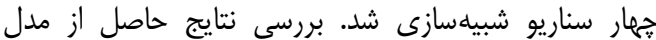

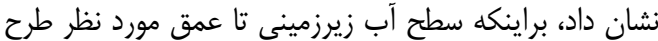

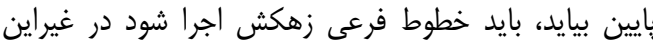

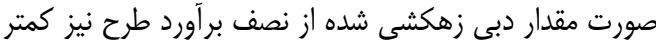

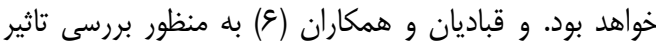

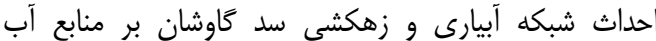

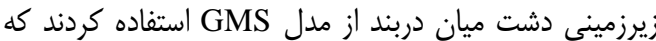

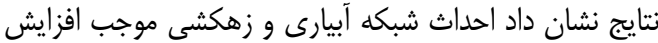

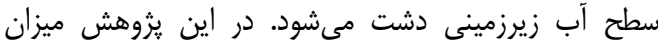

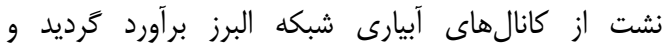

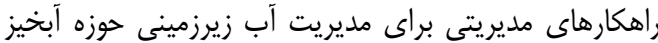

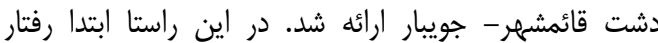

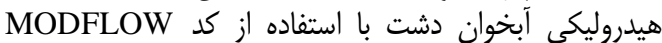

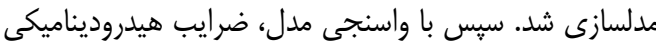

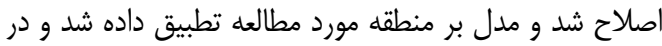

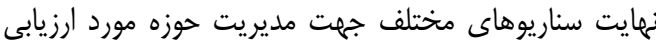

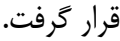

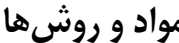
معرفى منطقه مورد مطالعه

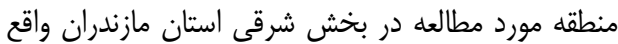

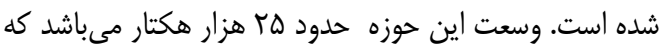

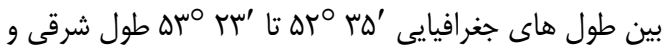

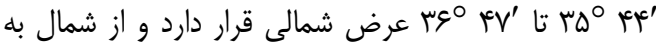

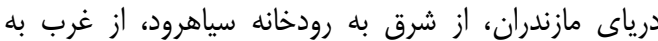

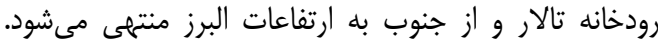

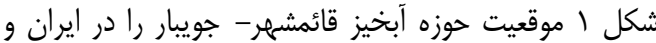

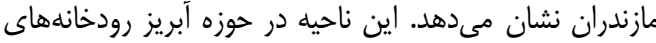

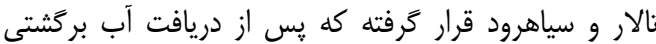

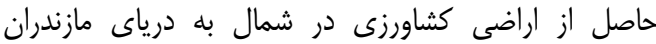

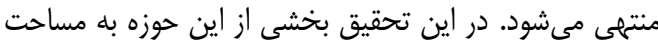

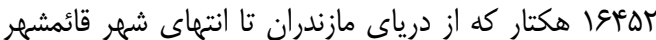

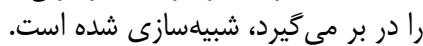

مدل عددى جريان آب زيرزمينى آبخوان دشت بهيبهان را با

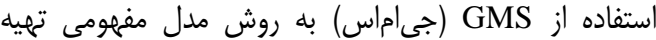

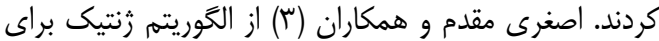

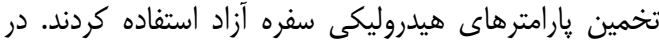

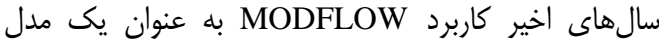

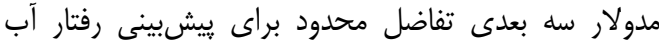
زيرزمينى توسعه بسيارى داشته است. اين مدل نتئ نتيجه سالها تحقيق در سازمان تحقيقات زمين شناسى آمريكا (USGS)

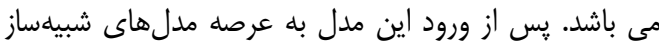

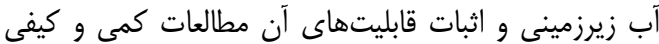

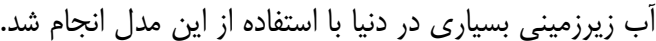

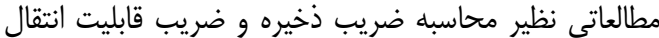

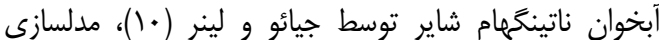

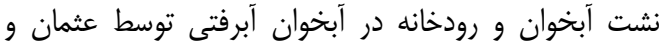

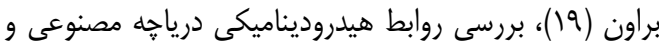

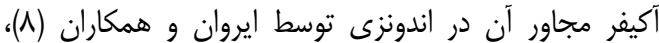
توسعه مدل عددى جريان آب زيرزمينى سله بعدى بان با استفاده

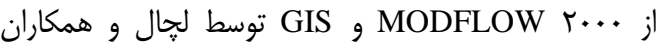
(1) و شبيهسازى آب زيرزمينى حوزه بلسو با با استفاده از تاز

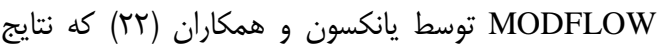

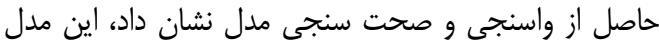

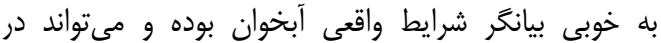

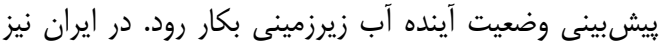

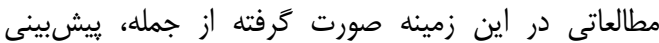

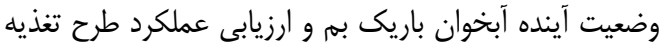

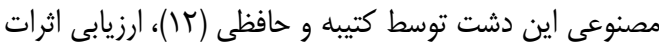

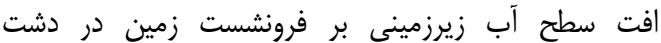

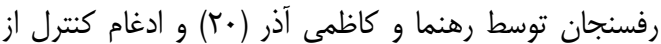

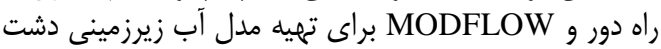

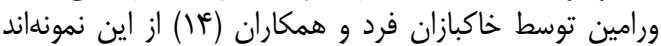

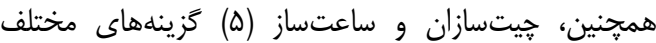

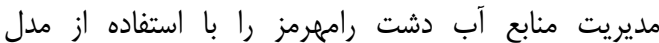

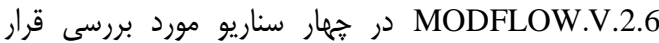

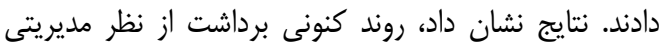

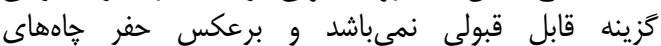

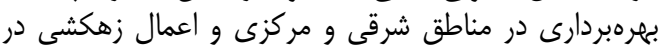
شمال و جنوب دشت كزينه مناسبى براى استفاده توأم منابع 

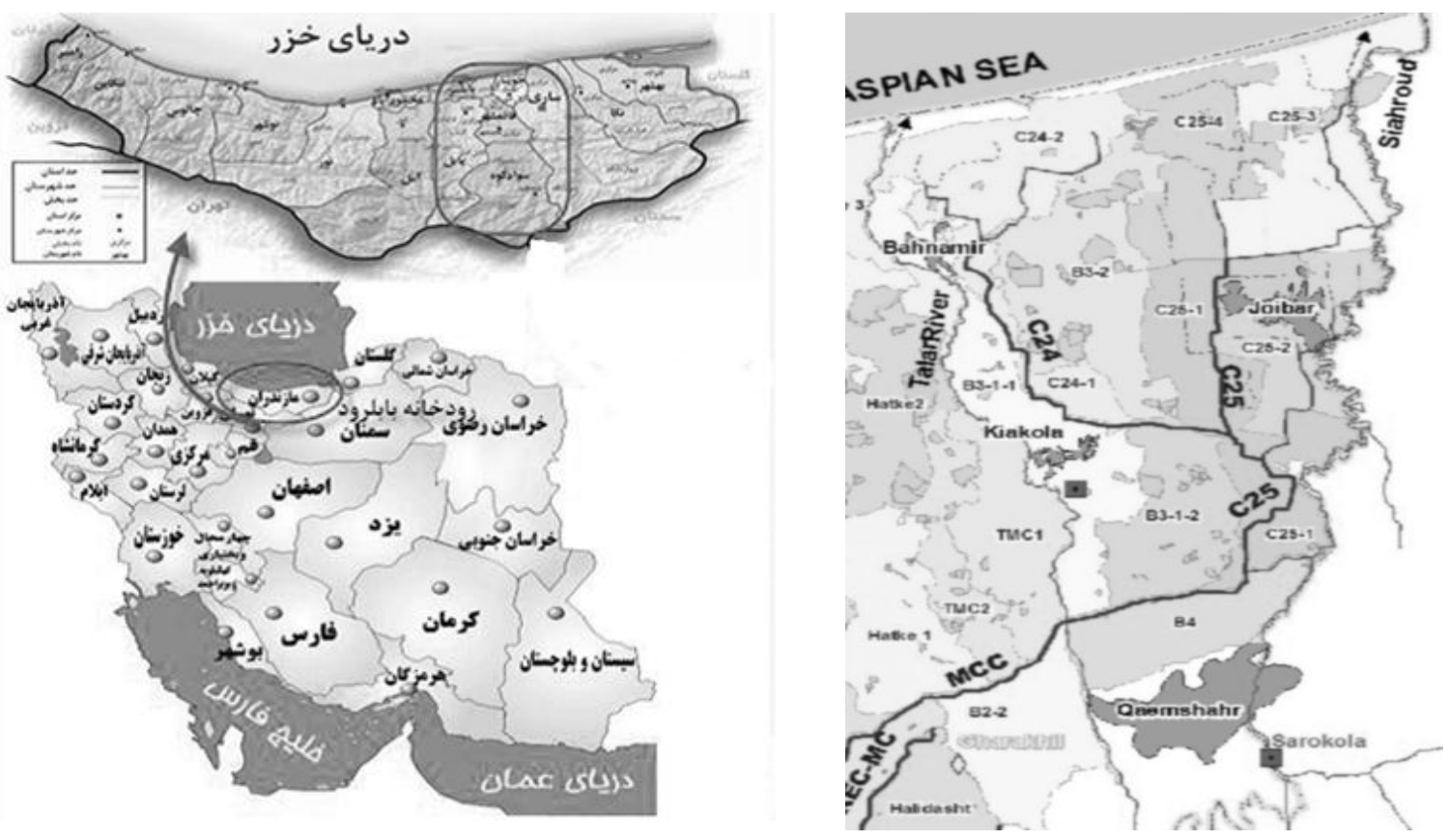

شكل ا- موقعيت دشت قائمشهر - جويبار در ايران و مازندران

Figure 1. Location of Ghaemshahr-Joybar catchmentin Iran and Mazandaran

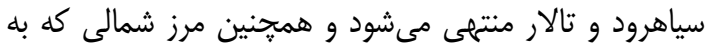

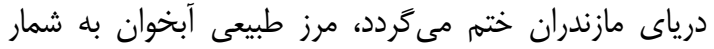

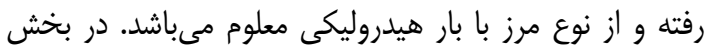

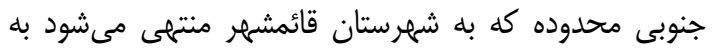

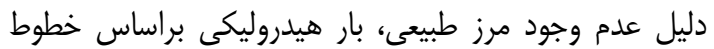

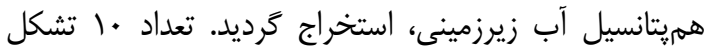
آببر با توجه به موضوع انتقال مديريت آبيارى (IMT)

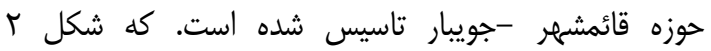

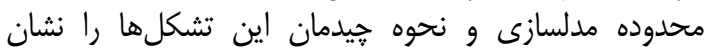

مدل مفهومى و مرزهاى آبخوان

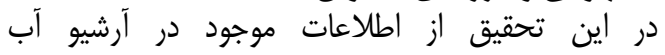

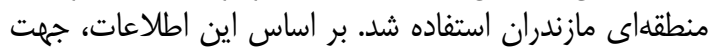

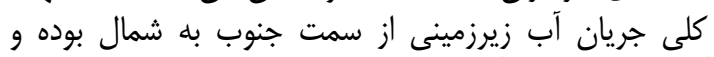

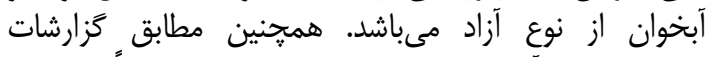

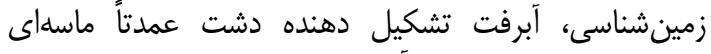

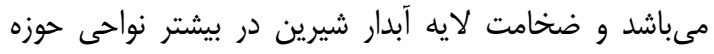

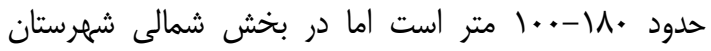
جويبار ضخامت اين لايه به صفر مى رسي رسد كه نش نشاندهنده

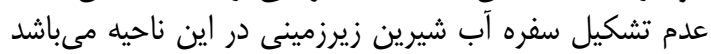

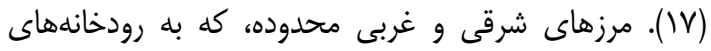

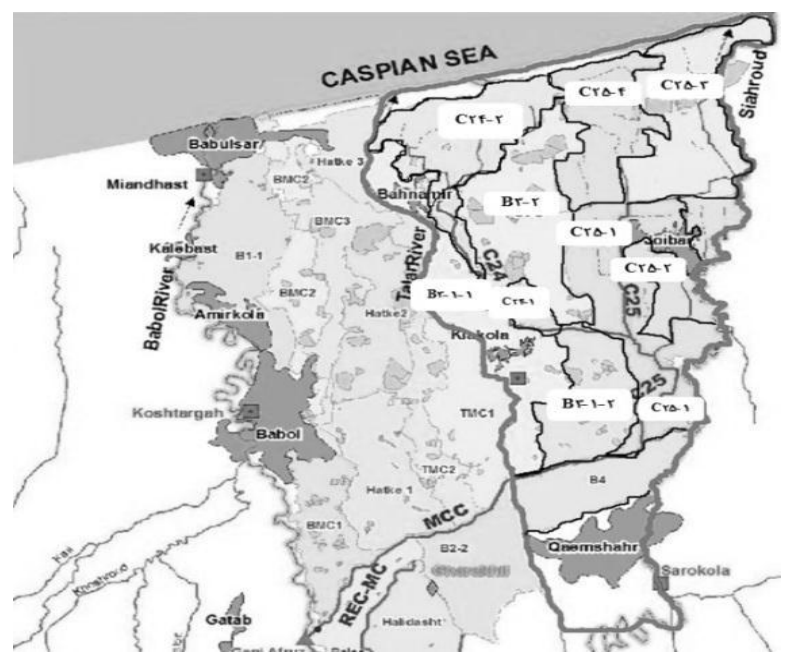

شكل r- موقعيت محدوده مدلسازى همراه با تشكلهاى آب بران

Figur 2. Location of modeling with water user association 
قبل از اجراى طرح آبيارى و زهكشى البرز، كل كشت منطقه،

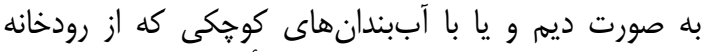
تالار در فصول غيرزراعى ير مى شوند، تأمينمى جاند.

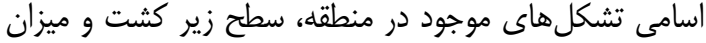

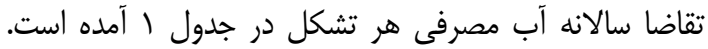

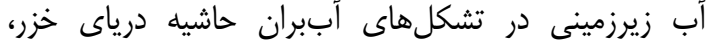
از از

Table 1. Area and water requirements of water user association

$$
\text { جدول ا - سطح زير كشت و نياز آبى تشكلهاى آببران }
$$

\begin{tabular}{|c|c|c|}
\hline تقاضا(ميليون متر مكعب) & مساحت(هكتار) & تشكل آببران (WUA) \\
\hline 1.19 & IQT & $\mathrm{C} 24-1$ \\
\hline TN/V & וזץ & C24-2 \\
\hline$r N / F^{\varepsilon}$ & אוזr & $\mathrm{C} 25-1$ \\
\hline $\mid N / 9$ & 1498 & $\mathrm{C} 25-2$ \\
\hline$r F / l$ & $9 \Delta \Delta$ & C25-3 \\
\hline TE/T & 115 & $\mathrm{C} 25-4$ \\
\hline$T V / T$ & ТQमॅ & B3-1-1 \\
\hline$r r / \Delta$ & TFY & B3-1-2 \\
\hline$r . / 1$ & $r \cdot \Delta \Delta$ & B3-2 \\
\hline$I V / \Delta$ & $r \cdot \Delta \Lambda$ & B4 \\
\hline YYT/q & ISTAT & مجموع \\
\hline
\end{tabular}

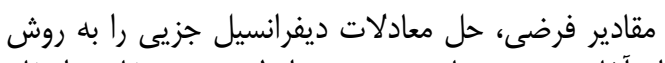

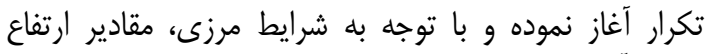

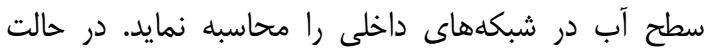

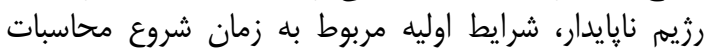

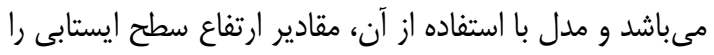
در كام زمانى بعدى، محاسبه مى كند.

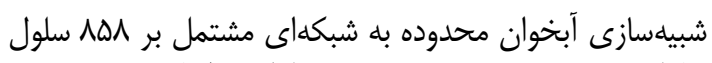

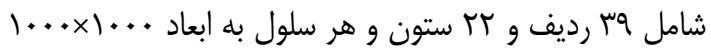

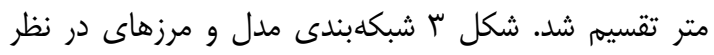

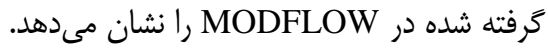

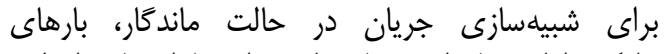
هيدروليكى اوليه نياز است تا مدل بتواند با استفاده از اين

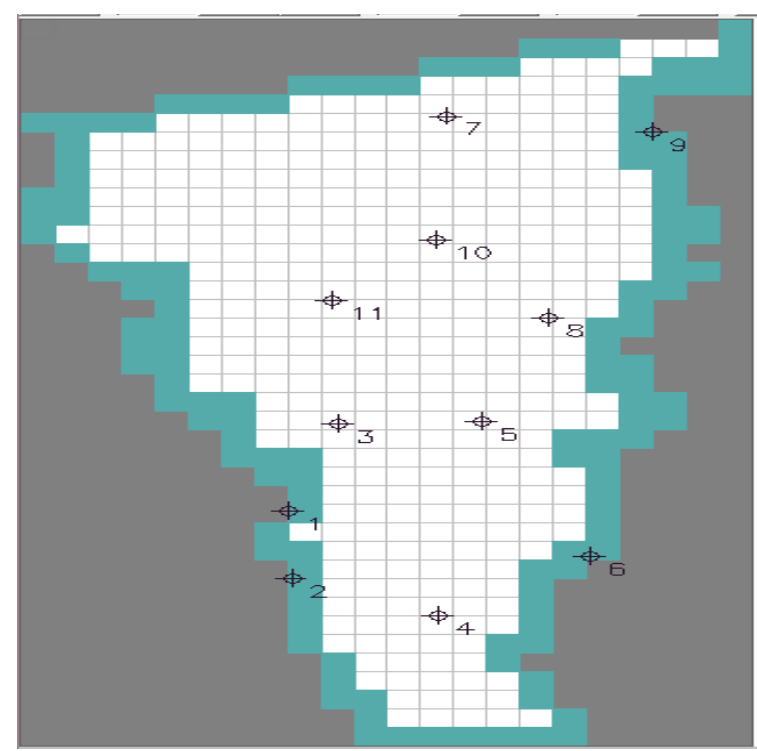

شكل س- شبكدبندى و موقعيت حاههاى مشاهدهاى دشت

Figure 3. Gridding and location of wells in the plain 
شده تا مقدار تغذيه از بارندگى در هر سلول بدست آيد. نفوذ از

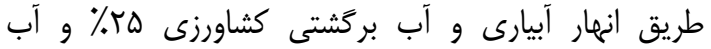

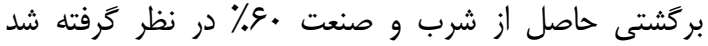

بسته جاه

براى محاسبه ميزان برداشت آب، از كليه حاهها در طول

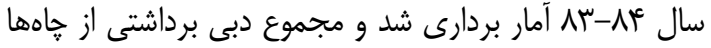

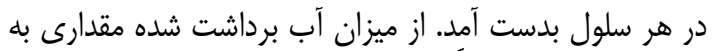

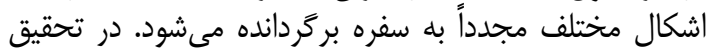

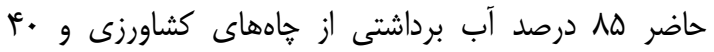

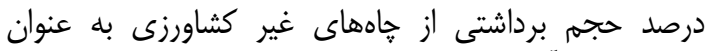
ميزان تخليه آب از سفره زيرزمينى لحاظ شد (1) (1).

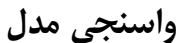

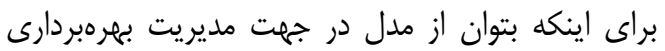

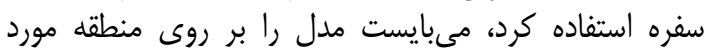

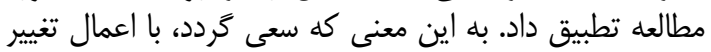

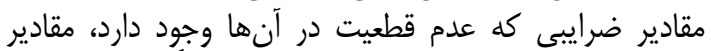

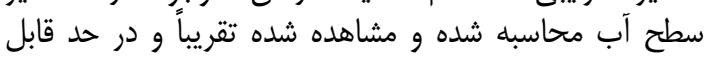

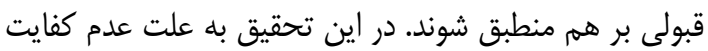

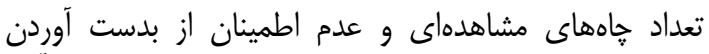

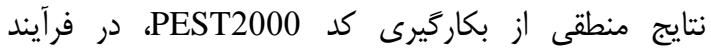
واسنجى مدل از روش تلفيقى سعى و خطا و اتوماتيكى استفاده

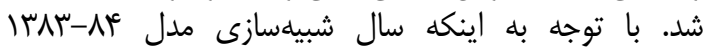

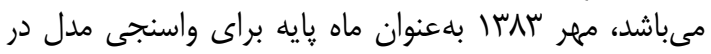

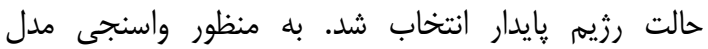

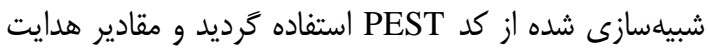

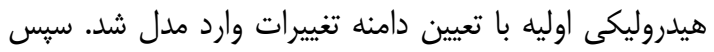

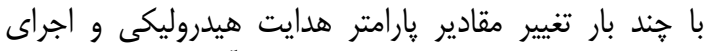

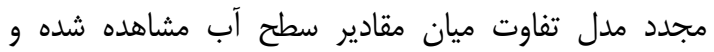

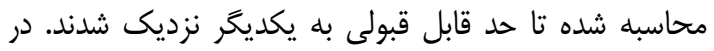

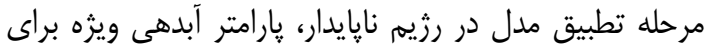

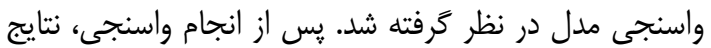

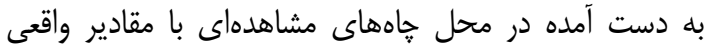
مقايسه كَرديد.

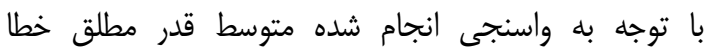

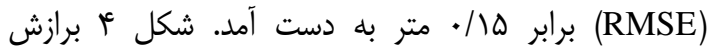

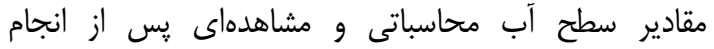
واسنجى مدل را نشان مى مهدي.

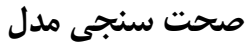

صحت سنجى، آزمون ضرايب به كار رفته دار در زمانهاى

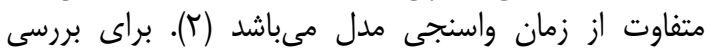

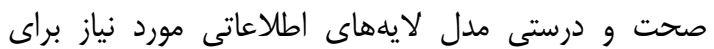

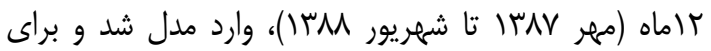

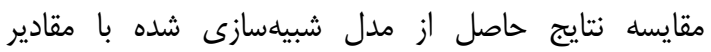
مشاهداتى معيار متوسط قدرمطلق خاصن خطا (RMSE) محاسبه

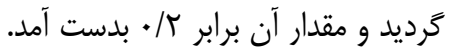

مقادير ارتفاع سطح ايستابى در ماه مهر سال سبرا كه ماه

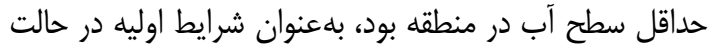

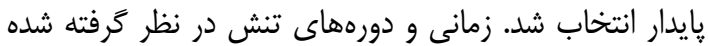

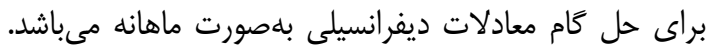

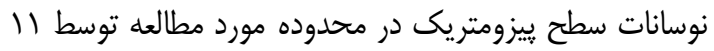

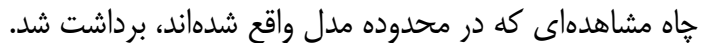

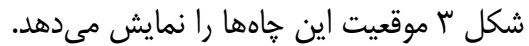

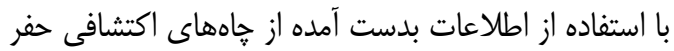

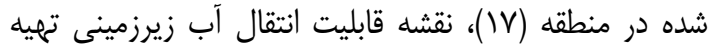

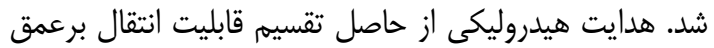

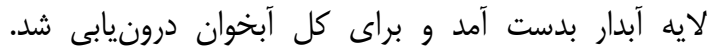

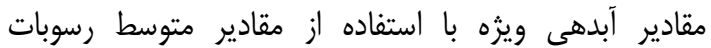

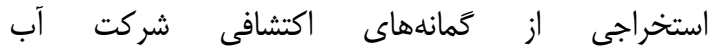
منطقامى مازندران بدست آمد (IV)

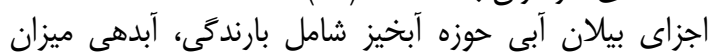

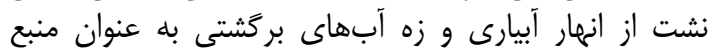

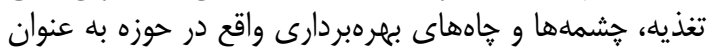

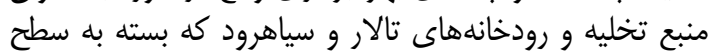

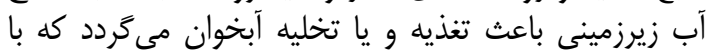
جهار بسته مستقل در مدل شبيهسازى شد. بسته تبخير - تعرق كشت غالب در حوزه آبخيزقائمشهر-جويبار برنج است.

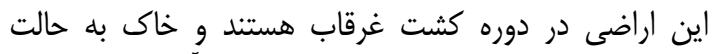

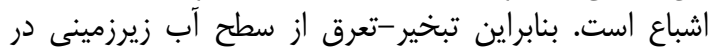

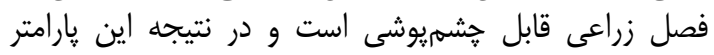

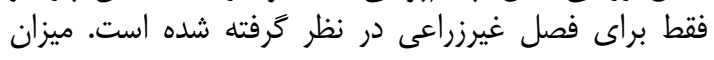

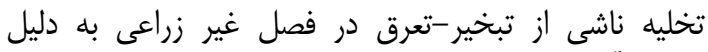

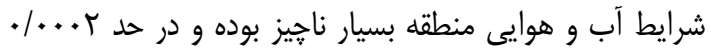

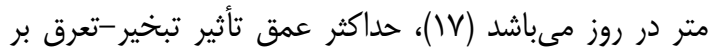
آبهاى زيرزمينى سه متر در نظر كَرفته شده است بسته رودخانه

با توجه به رقوم آب، رودخانهها يا باعث تغذيه آبخوان

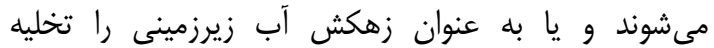

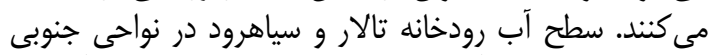

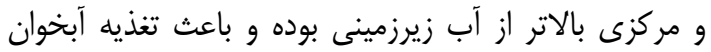

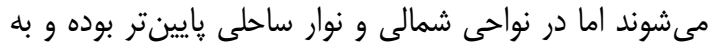

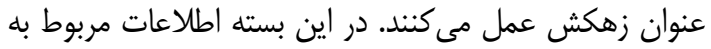

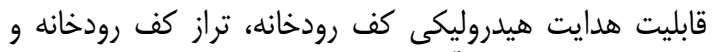

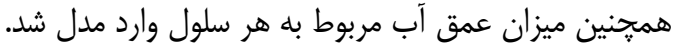
بسته تغذيه

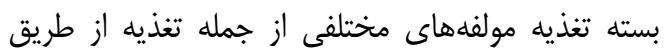

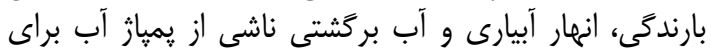

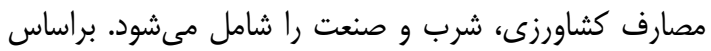

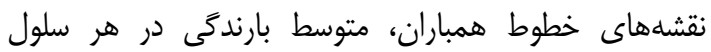

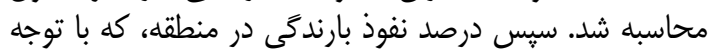

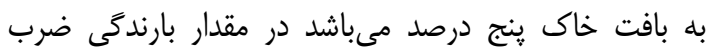




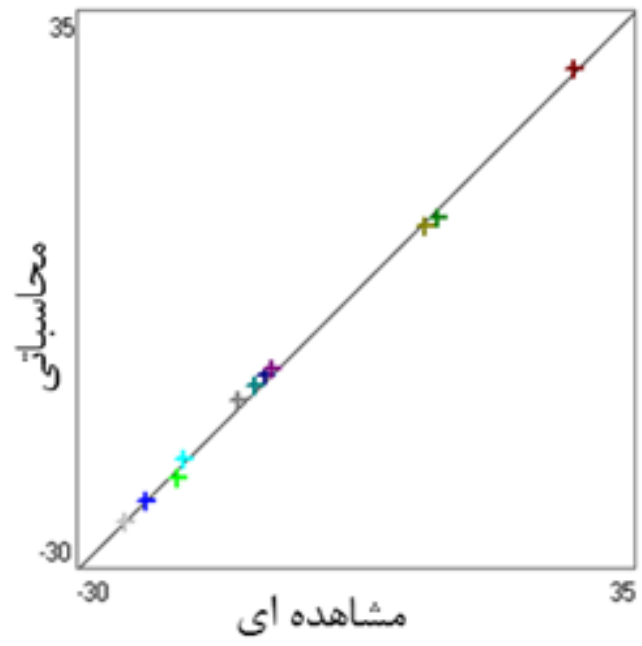

شكل f - برازش مقادير سطح آب محاسباتى و مشاهده ايى

Figure 4. curve fitting of calculated and observed Heads

Table 2. Hydrodynamic parameters of the aquifer after calibration

\begin{tabular}{|c|c|c|c|}
\hline قابليت انتقال (متر مربع بر روز) & آبدهى ويثه (\%) & هدايت هيدروليكى افقى (متر بر روز) & تشكل آببران دشت قائمشهر -جويبار \\
\hline$\Delta \cdot-r .$. & $\cdot 1 \cdot \Delta-\cdot 1 \cdot 1$ & t/T & C24-1 \\
\hline سות. & $\cdot 1 \cdot 1$ & $1 / \Delta \Delta-\Gamma / \Delta \Lambda$ & C24-2 \\
\hline $1 \cdots-\Lambda \cdots$ & $\cdot|\cdot \Lambda-\cdot| r \mid$ & $r / r-\Lambda$ & C25-1 \\
\hline$\Delta \cdot-r \cdot \cdot$ & $\cdot / \cdot 1-\cdot / T r$ & $1 / \Lambda \Delta-r / \& V$ & C25-2 \\
\hline . & $\cdot \mid \cdot+-\cdot / \cdot 1$ & $T / T r-r / T \Lambda$ & C25-3 \\
\hline . & $\cdot 1 \cdot 1$ & $1 / \Lambda \Delta-r / \Delta$ & C25-4 \\
\hline $1 \cdots-1 \ldots$ & $\cdot 1 \cdot 0-\cdot 1 \cdot 9$ & T/Tr-D & B3-1-1 \\
\hline$f \ldots-q \ldots$ & $\cdot|\cdot r-\cdot| r \mid$ & $F / \Delta \Lambda-1$. & B3-1-2 \\
\hline$\cdot-1$. & $\cdot 1 \cdot 1$ & $1 / \perp \Delta-\Gamma / \Delta$ & B3-2 \\
\hline$\Lambda \cdot \cdot-1 \cdot \Delta$. & $.1+4-+1 \cdot 9$ & $1+-r$. & B4 \\
\hline
\end{tabular}

گرفت. بدين منظور آمار و اطلاعات عوامل تغذيه و تخليه

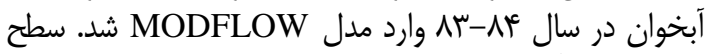

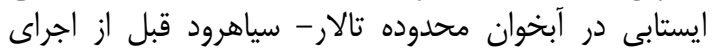

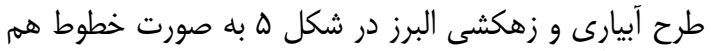

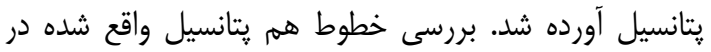

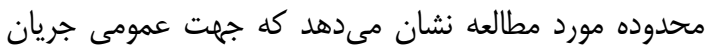

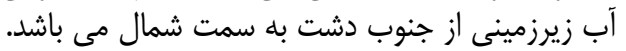

در جدول r مقادير يارامترهاى هيدروديناميكى آبخوان

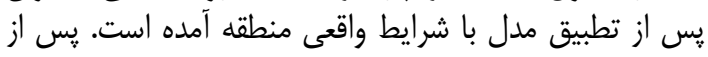

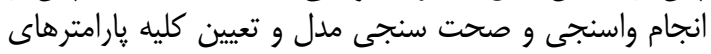

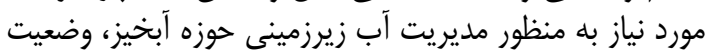

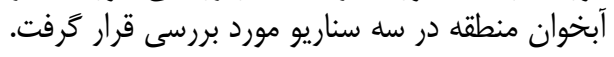

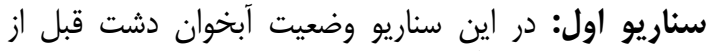

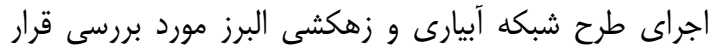




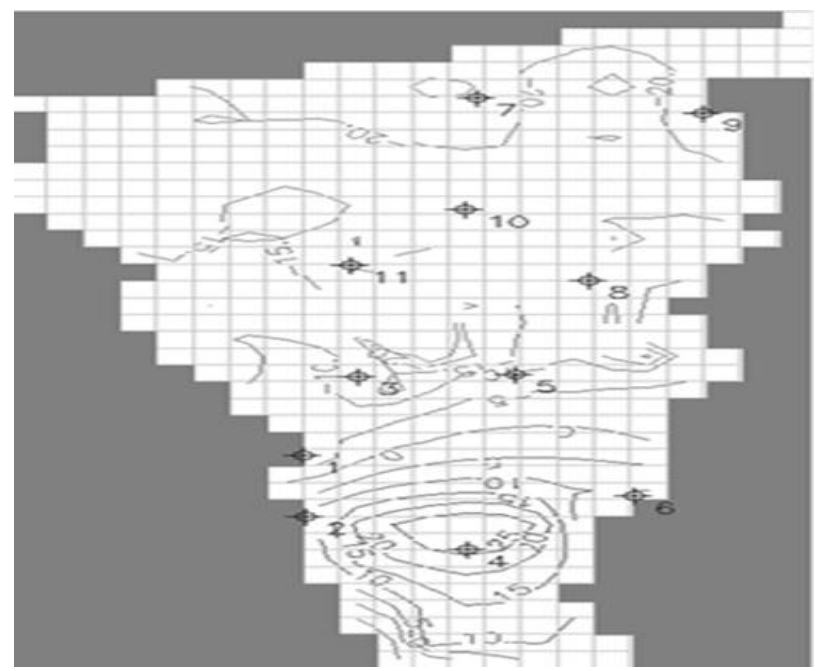

شكل ه- سطح ايستابى آبخوان قبل از اجراى شبكه آبيارى و زهكشى البرز

Figure 5. Water table Aquifer before alborz irrigation and drainage network performance

شبيهسازى شده به ازاى مقادير مختلف تخليه آب زيرزمينى

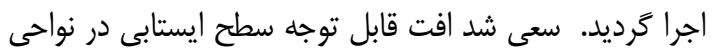

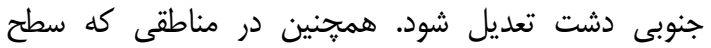

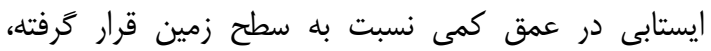

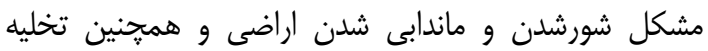

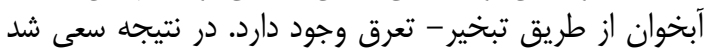

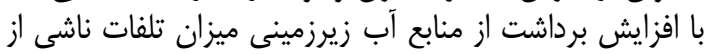

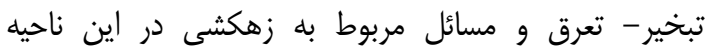

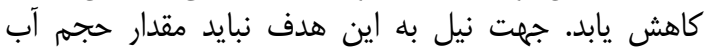

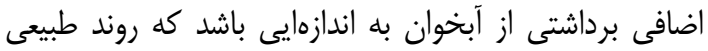

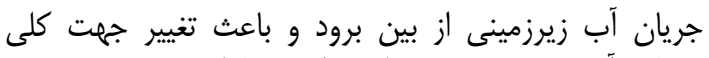

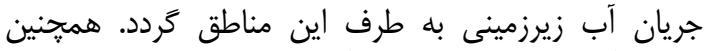

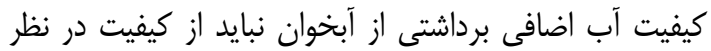

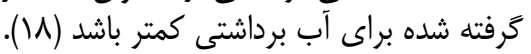

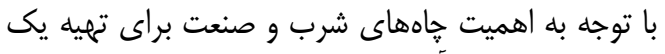

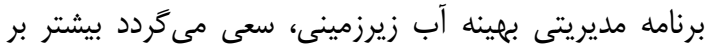

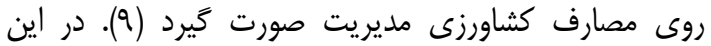

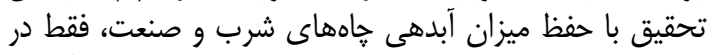

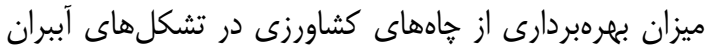

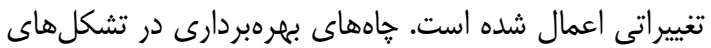

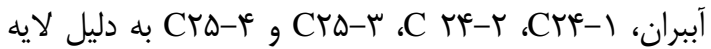

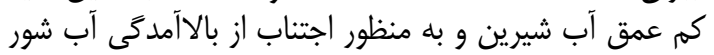

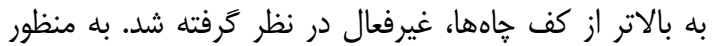

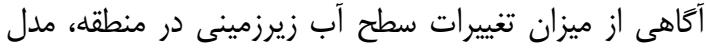

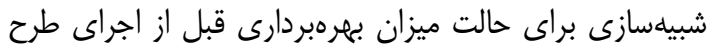

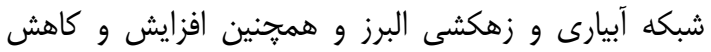

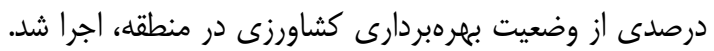

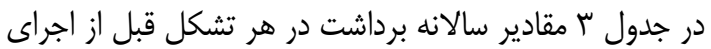
طرح شبكه آبيارى و زهكشى البرز آورده شده است. زدر اين سناريو به منظور بررسى تأثير اجراى شبكه آبيارى

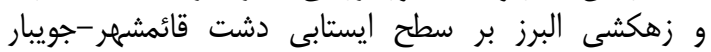
مقادير نشت از كانالهاى آبيارى شبكه البرز به بـته بـائه تغذيه

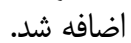

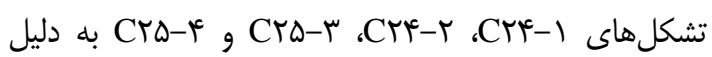

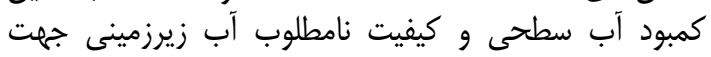

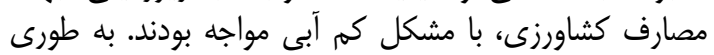

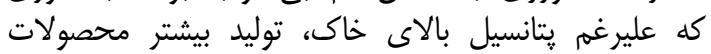

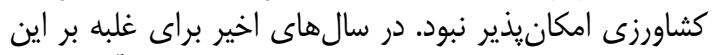

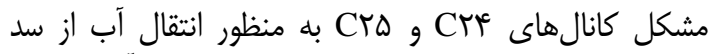

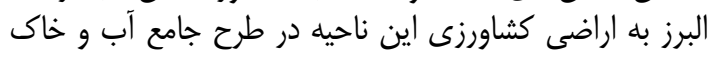

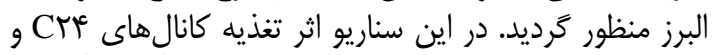

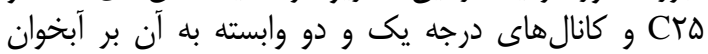

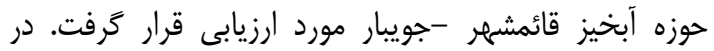

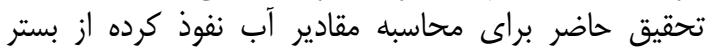
كانالهاى بتنى از رابطه ديويس و ويلسون (1) استفاده شد. $\mathrm{S}=0.45 * \mathrm{C} * \mathrm{~h}^{1 / 3} /\left(4 * 10^{6}+3.650 * \mathrm{~V}^{1 / 2}\right) \quad$ (l) در اين رابطه

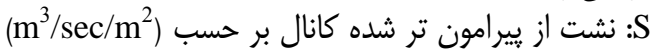

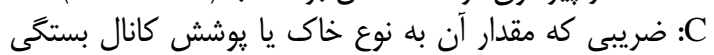
دارد

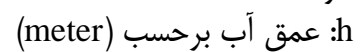

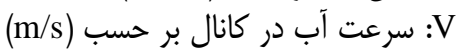

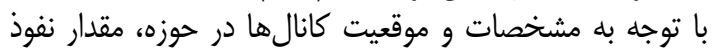

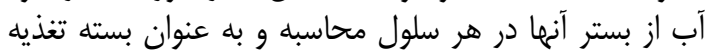
وارد مدل گرديد. سناريو سوم مدر ارد در اين سناريو به منظور بدست آوردن حداكثر مقادير مجاز

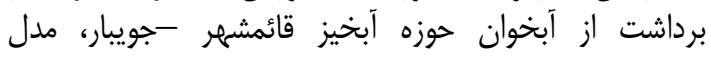



Table 3. Annual withdrawal of groundwater before Alborz Irrigation and Drainage Network Performance

\begin{tabular}{|c|c|}
\hline برداشت سالانه قبل از اجراى طرح (ميليون متر مكعب) & تشكلهاى آبران \\
\hline$r / r$ & $\mathrm{C} 24-1$ \\
\hline$r / r$ & $\mathrm{C} 24-2$ \\
\hline N/F. & $\mathrm{C} 25-1$ \\
\hline $1 / \Delta$ & $\mathrm{C} 25-2$ \\
\hline$\cdot / 9$ & $\mathrm{C} 25-3$ \\
\hline $1 / 9$ & C25-4 \\
\hline R & B3-1-1 \\
\hline$\Delta r$ & B3-1-2 \\
\hline $8 / \pi$ & B3-2 \\
\hline$\Delta / 1$ & B4 \\
\hline Ar & مجموع برداشت ساليانه \\
\hline
\end{tabular}

بعد از اجراى طرح شبكه آبيارى و زهكشى البرز سطح ايستابى لئ

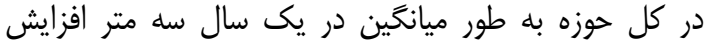

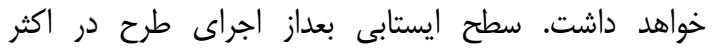

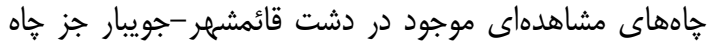

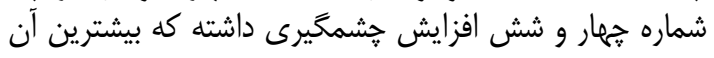

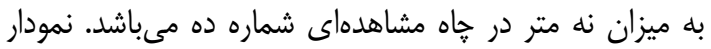

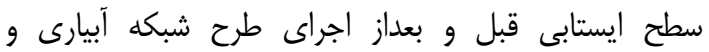
زهكشى البرز در شكل و نمايش داده شده است.
نتايج و بحث سناريو اول: نتايج حاصل از سناريو اول نشان داد، ارتفاع

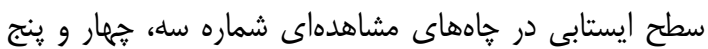

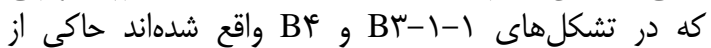

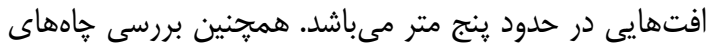

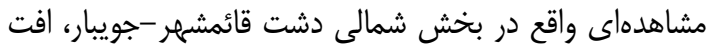

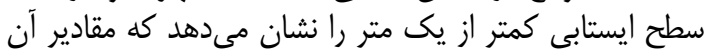

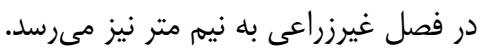
سناريو دوم: نتايج حاصل از سناريو دوم نداكى ازئ آن است

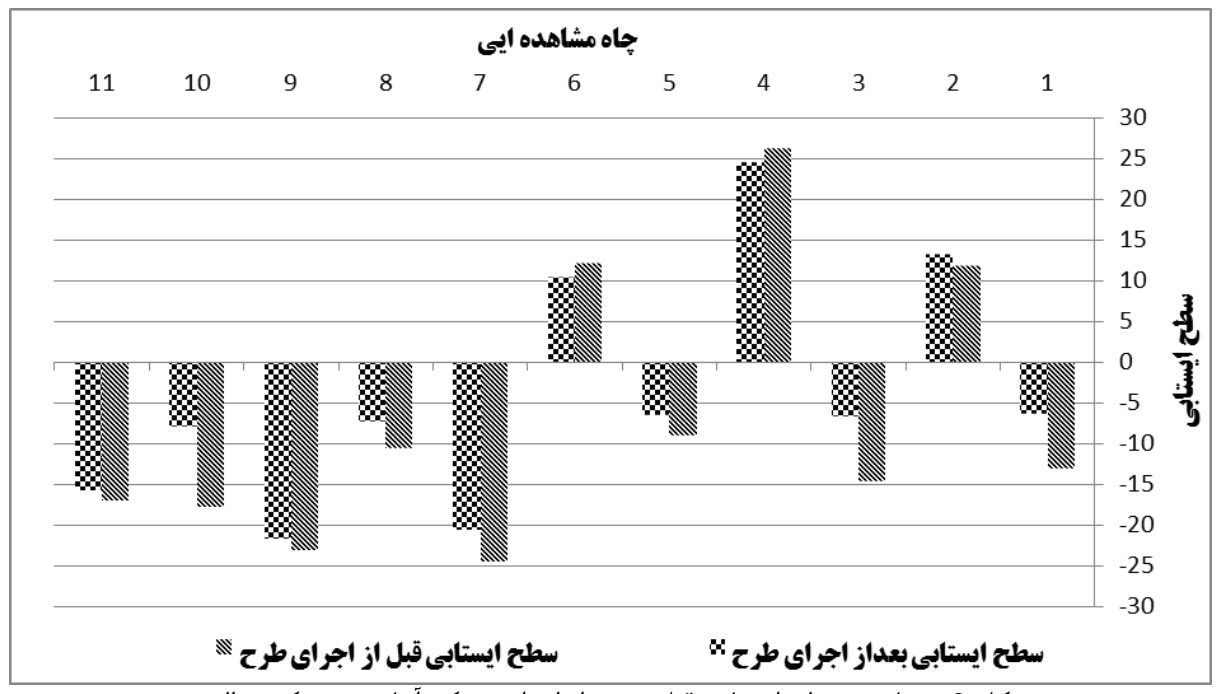

شكل 9- مقايسه سطح ايستابى قبل و بعد از اجراى شبكه آبيارى و زهكشى البرز

Figure 6. Compare of water heads before and after Alborz Irrigation and Drainage Network Performance

كشاوزى مى باشد بسيار ناجيز بوده علاوه براينكه شبكه

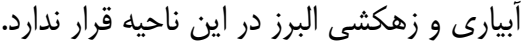

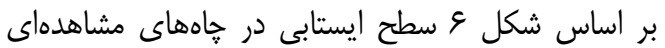

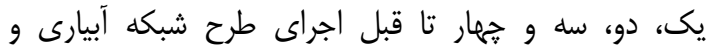

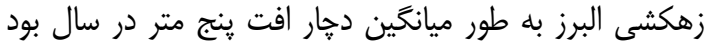

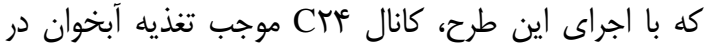

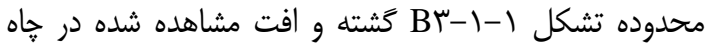

خيز سطح ايستابى در خاه شماره •إ به داله دليل تراكم كانالهاى انتقال آب درجه يك و دو دان در اين ناحيه مى إباشد. اما

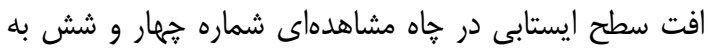

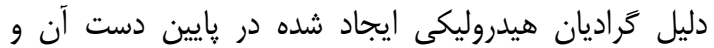

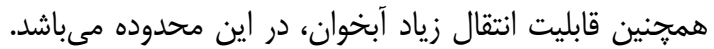

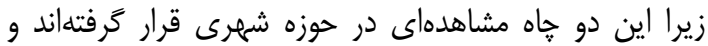
تغذيه آبخوان در اين بخش نسبت به دايه دير نواحى كه 


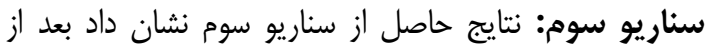

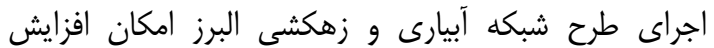

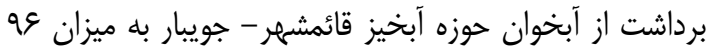

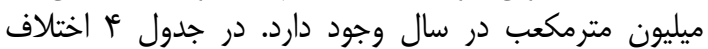

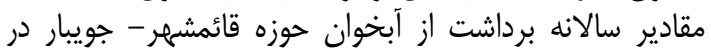

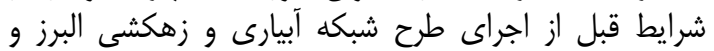

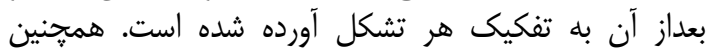

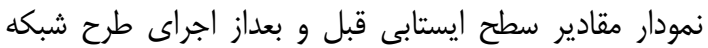

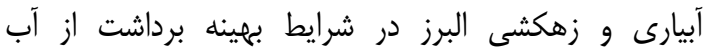
زيرزمينى حوزه قائمشهر -جويبار در شكل Vا آورده شده است.
مشاهدهايى شماره يك، دو و سه برطرف مى تردد اما به

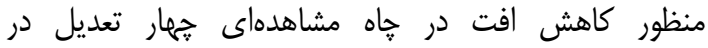

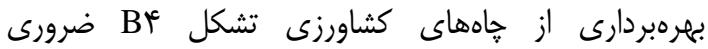
تبا بهرهبردارى از كانال هاى CYF و CTR مشكل كمبود آب تشكلهاى

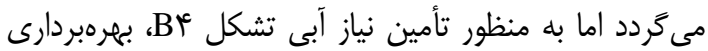

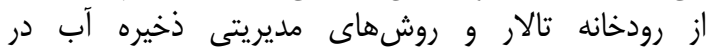

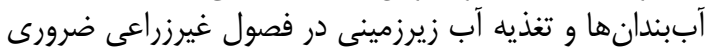

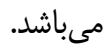

جدول عا- اختلاف مقادير سالانه برداشت در شرايط قبل و بعد از اجراى شبكه آبيارى و زهكشى البرز Table 4.Difference in annual withdrawal under before and after Alborz Irrigation and Drainage Network Performance

\begin{tabular}{|c|c|c|c|}
\hline اختلاف مقادير برداشت بعد از اجراى طرح با قبل & 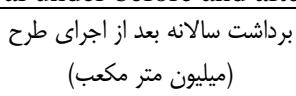 & $\begin{array}{c}\text { برداشت سالانه قبل از اجراى طرح } \\
\text { (ميليون متر مكعب) }\end{array}$ & \\
\hline$-r / \mu$ & . & $\Gamma / \mu$ & C24-1 \\
\hline$-r / r$ & . & $r / r$ & C24-2 \\
\hline rN/T & $\Delta s / \Lambda$ & $\mid N / 9$ & C25-1 \\
\hline v & $N / \Delta$ & $1 / \Delta$ & $\mathrm{C} 25-2$ \\
\hline.$- / 9$ & . &.$/ 9$ & $\mathrm{C} 25-3$ \\
\hline$-1 / 8$ & . & $1 / 9$ & C25-4 \\
\hline$I V / T$ & i) & 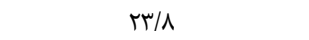 & B3-1-1 \\
\hline tr & $i \Delta$ & 11 & B3-1-2 \\
\hline $19 / \mathrm{V}$ & זr & $s / \pi$ & B3-2 \\
\hline$-1 / \pi$ & $\Gamma / \Lambda$ & $\Delta / 1$ & B4 \\
\hline 99 & IVA & Nr & مجموع برداشت ساليانه \\
\hline
\end{tabular}

برداشت در تشكلهاى Iو و

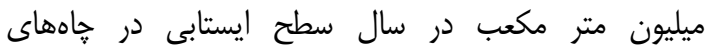

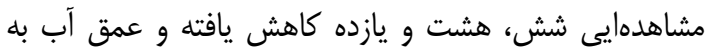

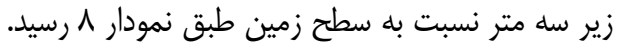

همانطور كه در اين شكل نشان داده شده با حذف خاههاى بهرهبردارى تشكل هاى

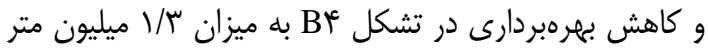

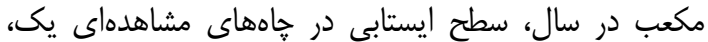

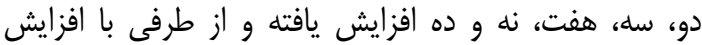




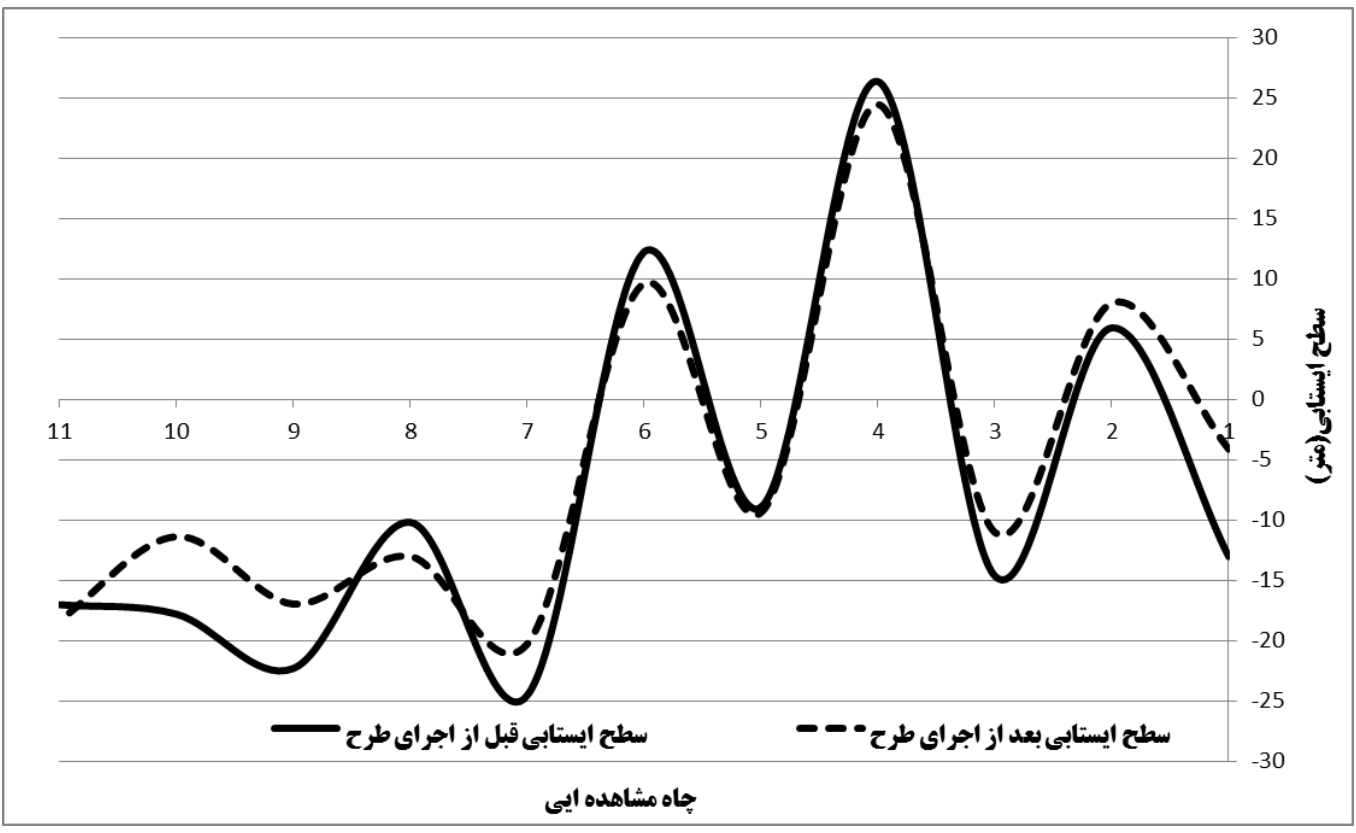

شكل V- مقايسه مقادير سطح ايستابى قبل و بعد از اجراى طرح شبكه آبيارى و زهكشى البرز در شرايط بهينه برداشت از آب زيرزميني

Figure 7. Comparison water heads in withdrawal groundwater optimal conditions under before and after Alborz Irrigation and Drainage Network Performance

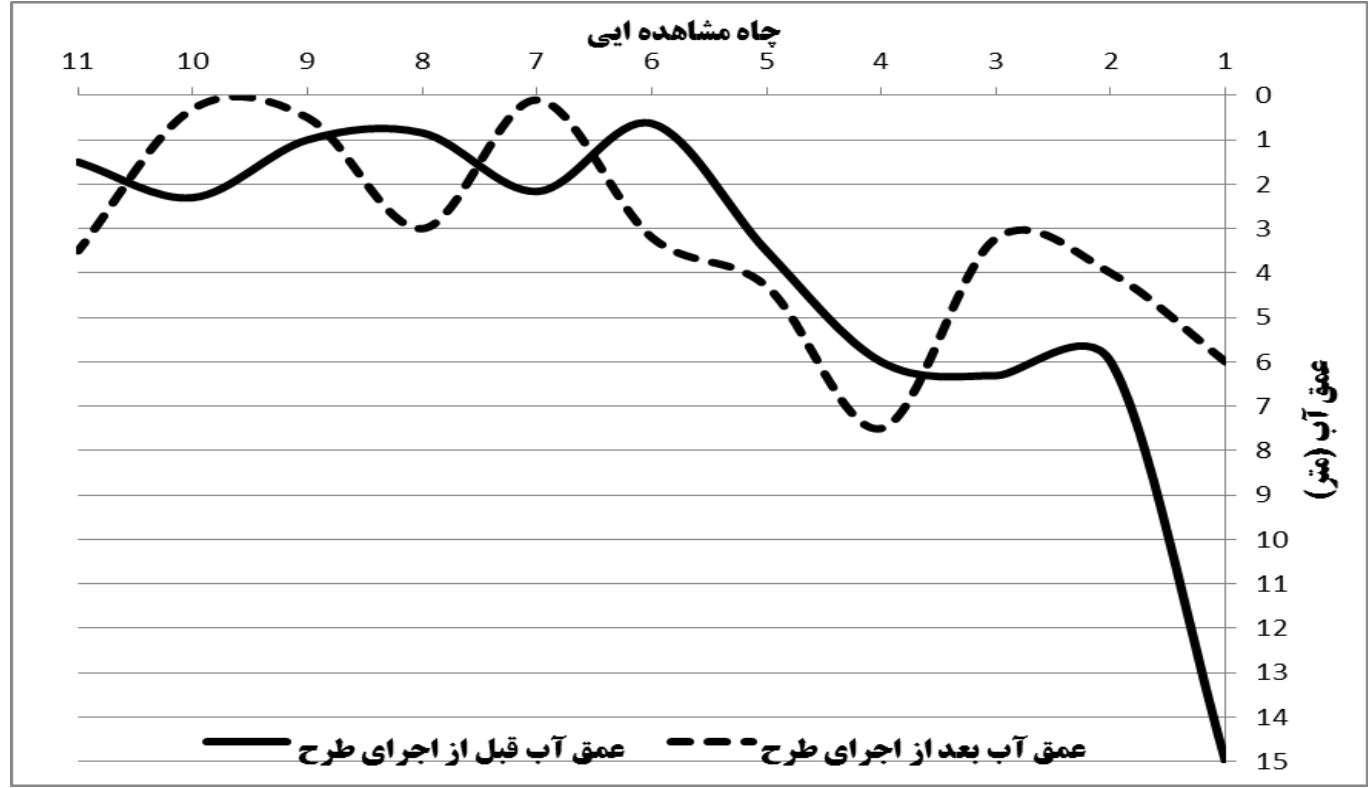

شكل ^- مقايسه عمق آب قبل و بعد از اجراى طرح شبكه آبيارى و زهكشى البرز در شرايط بهينه

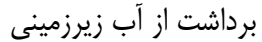

Figure 8. Comparison water depth in withdrawal groundwater optimal conditions under before and after Alborz Irrigation and Drainage Network Performance

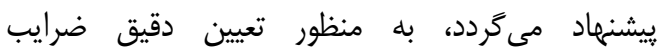

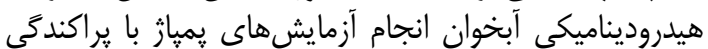

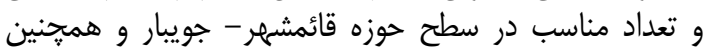

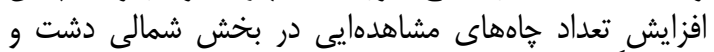
خصوصاً در نزديكى رودخانها مشا به منظور تعيين رفتار رونال روخانه

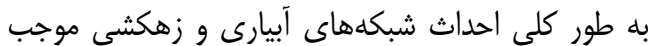

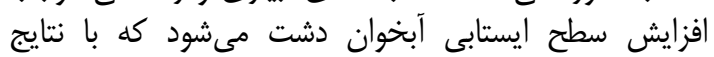

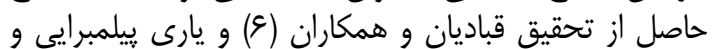

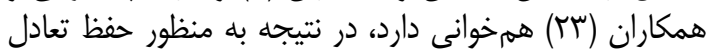

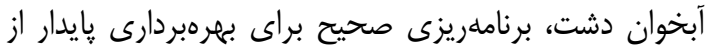

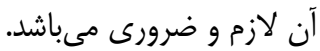


از آن به منظور جلوكيرى از ييشروى آب شور دريا به سمت

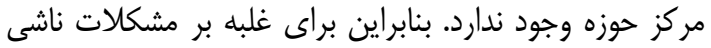

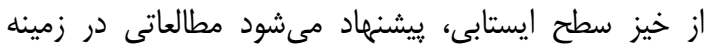

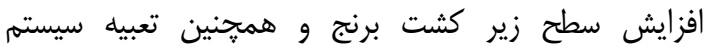

زهكشى در اين حوزه آبخيز انجام گيرد.
به عنوان عامل تغذيه يا تخليه سفره در نقاط مختلف ييشنهاد

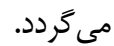

همجنين تجاه مشاهدايیى شماره هفت و ود ده در تشكل

T CTD-Y بعداز اجراى طرح با خيز سطح ايستابى مواجه است.

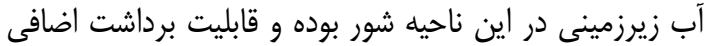

1. Anderson, E.I. 2005. Modeling groundwater-surface water interactions using Dupuit approximation. journal of Approximation advances in water resources, 28: 315-327.

2. Anderson, M.W. Woessner. 1992. Applied groundwater modeling flow and adjective transport. Academic Press, San Diego, 381 pp.

3. Asghari moghadam, A.,V. Nourani and M. Kord. 2009. Using genetic algorithm of estimate hydraulic parameters of unconfined aquifers. journal of Water and wastewater, 69: 73-79 (In Persian).

4. Bakker, M. 1999. Simulating groundwater flow in multi- aquifer systems with analytical and numerical Dupuit models. journal of hydrology, 222: 315-327.

5. Chitsazan, M. and M. Saatsaz. 2005. Application of mathematical models MODFLOW in the study of different options water resources management of Ramhormoz plain. journal of sciences Shahid Chamran University, 14(B): 1-15 (In Persian).

6. Ghobadiyan, R., A. Fatahicheghabgi and M. Zare. 2014. Studying the Effects of Gavoshan Dam's Irrigation and Drainage Network on Groundwater of Miandarband Plain Using GMS 6.5 Model, journal of water research in agriculture 28(4): 759-772 (In Persian).

7. Heydarian, S.A. 2007. Irrigation management transfer principles and methodology. 1nd. edn., Tehran, Iran, 228 pp (In Persian).

8. Irawan, D.E., D.J. Puradimaja and H. Silaen. 2011. Hydrodynamic relationship between Man- Made Lake and surrounding aquifer, Cimahi, Bandung Indonesia. $10^{\text {th }}$ International Conference on Civil and Environmental Engineering, Capetown, South Africa 58: 100-104.

9. Janat rostami, S., M. Kholghi, K. Mohammadi and M. Malmir. 2011. Operational management of Shahrekord plain aquifer. The $6^{\text {th }}$ National Congress on Civil Engineering, Semnan, Iran, 8 pp (In Persian).

10. Jiao, J.D. and N. Leaner. 1996. Using sensitivity analysis to assist parameter zonation in ground water flow model. Journal of the American water resources association, 32(1): 75-78.

11. Karimipour, A.Gh., R. Rakhshandehroo and G. Banitalebi Dehkordi. 2011. Evaluating the performance of drainage system in dropping water table elevation in Shiraz plain. journal of Water and wastewater, 2: 30-41 (In Persian).

12. Katibeh, H. and S. Hafezi. 2004. Application of MODFOW in groundwater management and evaluation of artificial recharge project of $\mathrm{AB}$-barik aquifer (Bam). journal of Water and wastewater, 50(1): 45-58 (In Persian).

13. Kazbekov, J., I. Abdullaev, H. Manthrithilake. A. Qureshi and K. Jumaboev. 2009. Evaluating planning and delivery performance of Water User Associations (WUAs) in Osh Province, Kyrgyzstan. journal of Agricultural water management, 96: 1259-1267.

14. Khakbazan Fard, F., A. Abdolghafoorian and M. Tajrishy. 2012. Using hydrological model and energy balance estimating groundwater table, case study: Varamin plain. $9^{\mathrm{m}}$ International Congress on Civil Engineering, Isfahan, Iran, $8 \mathrm{pp}$.

15. Knowles, I. and A. Yan. 2007. The reconstruction of groundwater parameters from head data in an unconfined aquifer. journal of Computational and applied mathematics, 208(1): 72-81.

16. Lachaal, F., A. Mlayah, M. Bedir, J. Tarhouni and Ch. Leduc. 2012. Implementation of a 3-D and GIS tools: The Zeramdine- Beni Hassen Miocene aquifer system (east-central Tunisisa). Journal of Computers \& Geosciences, 48(2012): 187-198.

17. Nespak, 2012. Basin Water Plan and Scenario Analysis, Alborze Integrated Land and Water management Project. IWREMS Consultants, National Engineering Services Pakistan and Tarh Tadbir Engineering Company, Mazandarn, Iran, 95 pp (In Persian).

18. Nikbakht, J. 2006. Modeling of conjunctive use of surface and groundwater under quality and quantity constraints. Ph.D. thesis. Tarbiat modares university, Tehran, Iran, $228 \mathrm{pp}$ (In Persian).

19. Osman, Y.Z. and M.P. Bruen. 2002. Modeling stream - aquifer seepage in an alluvial aquifer: an improved loosing stream package for MODFOLW. journal of Hydrology, 264: 69-86.

20. Rahnam, B. and F. Kazemi Azar. 2006. Simulations groundwater flow of Rafsanjan plain using pmwin. The first regional conference of the Optimum Utilization of Water Resources, Shahrekord, Iran, 9 pp (In Persian).

21. Shahsavari, A. and K. Khodaei. 2005. Preparation groundwater flow model by using GIS of Behbahan Plain. $9^{\text {th }}$ Annual Meeting of the Geological Society of Iran, Tehran, Iran, $10 \mathrm{pp}$ (In Persian).

22. Yanxun. S., F. Yuan, Q. Hui and Zh. Xuedi. 2011. Research and Application of Groundwater Numerical Simulation-A Case Study in Balasu Water Source. journal of Procedia Environmental Sciences 8(2011): 146-152.

23. YariPilmaraei, E., S. Shaeri Karimi and R. Dadmehr. 2011. Reaction models of groundwater resource system in Zarineroud plain of the factor charging and discharging through irrigation and drainage network plain. $4^{\text {th }}$ conference of Iran water resource management, Tehran, Iran, 8 pp (In Persian). 


\title{
Simulation of Groundwater from Qaemshahr- Juibar Catchment under Performance of Alborz Irrigation and Drainage Network
}

\section{Zahra Ghorbani Sarhangi ${ }^{1}$, Ali Shahnazari ${ }^{2}$, Mohammad Ali Gholami Sefidkohi ${ }^{3}$ and Somayeh Jannat Rostami ${ }^{4}$}

1- M.Sc. of Irrigation and Drainage, Sari Agricultural Sciences and Natural Resources University

2- Associate Professor, Department of Water Engineering, Sari Agricultural Sciences and Natural Resources University (Corresponding Author: aliponh@yahoo.com)

3- Associate Professor, Department of Water Engineering, Sari Agricultural Sciences and Natural Resources University

4- Assistant Professor, Department of Water Engineering, College of Agriculture Sciences, University of Guilan Received: July 26, 2016 Accepted: November 26, 2017

\begin{abstract}
Incorrect management in Watersheds causes disorder of natural balance in groundwater resource and problems from water drawdown and consequences caused by non- optimum use of these water resources. In this research, in order to investigate the effect of construction of Alborz irrigation canals network on water table of Qaemshahr-Juibar Watershed and determination of maximum permissible water withdrawal from groundwater by water users associations of the region, in the condition of the performance Alborz network, the MODFLOW model was used. Besides the seepage water conveyance canals, recharge and discharge from the aquifer by Talar and Siahrood rivers, wells, return flow, rainfall and evaporation were all considered in the model. The model was run for a period time octobr 2004 to September 2004 in unsteady flow condition and was calibration with comparing observed and simulation water level. For model validation observations data for octobr 2008 to September 2008 was used the amount of RMSD was 0.2. after examined the model, the aquifer was evaluated in three scenarios: 1) Aquifer condition before alborz irrigation and drainage network performance, 2) after performance and 3) withdrawal groundwater optimal conditions. The results showed, after Alborz design performance, Rise of water table it was 3 meter for one year. And the possibility of creasing withdrawal from ground water resources was 96 million cubic meter per year.
\end{abstract}

Keywords: Aquifer Management, Maximum Permissible Withdrawal, MODFLOW Model Water User Association, Water Table 